\title{
Manifestação atípica da Doença de Paget em seio maxilar esquerdo: relato de caso
}

Atypical Paget Disease manifestation in left maxillary sinus: case report

Manifestación atipica de la enfermedad de paget en el seno maxilar izquierdo: reporte de caso

Vivian Bentes de OLIVEIRA

Lioney Nobre CABRAL

Tiago Novaes PINHEIRO

Myrian Salles VIEIRA

Antônio Jorge Araújo de VASCONCELOS II

Escola Superior de Ciências do Amazonas - Universidade do Estado do Amazonas, ESA-UEA, 69050-030 Manaus - AM, Brasil

\section{Resumo}

Introdução: A doença de Paget (DP) ou osteíte deformante é uma doença osteometabólica benigna, caracterizada pela reabsorção e deposição anormal e anárquica de osso, este osso é menos resistente e mais suscetível a fraturas. Objetivo: mostrar caso clínico de manifestação atípica de DP que afetou área de seio maxilar (maior intensidade) e outras regiões como cóccix, tubérculo ilíaco direito e esquerdo e articulação sacroilíaca direita e esquerda, numa paciente do sexo feminino de 63 anos que queixava dor em hemi-maxila esquerda com aumento progressivo local desde a juventude. Esta acometia região dos dentes remanescentes ipsilaterais 23 e $24 \mathrm{com}$ doença periodontal crônica grave. Material e método: Por exames de imagem observou hiperdensidade que preenchia quase toda a extensão do seio maxilar esquerdo com áreas de hipodensidade e na cintilografia apresentava maior captação de radiofármaco também nesta localização. Para elucidação diagnóstica, cujas hipóteses contemplavam, além de DP, também tumor marrom do hiperparatiroidismo e osteossarcoma, foram solicitados exames laboratoriais: TSH, creatinina, PTH, T3, T4, fosfatase alcalina, albumina, microalbumina, TGP, cálcio sérico, aldolase e calcitonina que não apresentaram nenhuma alteração, sendo indicada a biopsia incisional para análise histopatológica e conclusão diagnóstica. Resultado: Feita a interrelação das características clínicas, laboratoriais, imagenológicas e exame histopatológico, obteve-se diagnóstico de DP. Conclusão: Após diagnóstico, paciente foi encaminhada para tratamento reumatológico. O tratamento ordinariamente transcorre com o uso de bifosfonatos para redução da remodelação óssea, sendo amplamente usado o ácido zoledrônico além de analgésicos para o controle da dor.

Descritores: Osteíte Deformante; Diagnóstico por Imagem; Difosfonatos.

\section{Abstract}

Introduction: Paget disease of bone (PD) or osteitis deformans is a benign pathology of bone metabolism characterized by irregular and anarchic bone remodeling which may result in weakness and greater susceptibility to pathologic fractures. Objective: report the uncommon clinic manifestation of PD which affected more intensive maxillary sinus area and others regions as coccyx, bilateral iliac tuberculosis and sacroiliac joints in a 63-year-old female patient who had the complaint of left maxilla pain accompanied by volume increase in 23 and 24 dental elements area since girlhood with chronic periodontal disease. Materials and methods: By image exams was verified radiopacities in almost all left maxillary sinus region with hypodensity zones and scintigraphy shows high concentration of radiopharmaceuticals in this area. To correct diagnosis witch hypotheses were, including PD, brown tumor associated with hyperparathyroidism and osteosarcoma were requested laboratorial exams: TSH, creatinine, PTH, T3, T4, alkaline phosphatase, albumin, microalbumin, TGP, serum calcium, aldolase and calcitonin showing no abnormality, incisional biopsy was performed and the material send to histopathological analysis and diagnose conclusion. Results: correlating clinical, biochemical, imagenological and histopathologic findings a final diagnosis of PD was established. Conclusion: after diagnosis, pacient was referred to rheumatological treatment. The therapy usually consists of biphosphonates use to reduce the intense bone metabolism witch most common zoledronic acid besides analgesics for pain control.

Descriptors: Osteitis Deformans; Diagnostic Imaging; Diphosphonates.

\section{Resumen}

Introducción: la Enfermedad de Paget (DP) o osteites deformante es una enfermedad osteometabólica benigna, caracterizada por la reabsorción y deposición anormal del hueso, este es menos resistente y más suceptible a fractura. Objetivo: mostrar caso clinico de manifestaión atípica DP que afecto el area del seno maxilar (mayor intensidad) y otras regiones como el coxis, turbeculo iliaco derecho e izquierdo y la articulación sacroiliaca derecha e izquierda en una paciente del sexo femenino de 63 años que quejaba de dolor en el maxilar izquierdo con aumento progresivo localizado desde la juventud que comprometia la región de los dientes remanente en el mismo lado 23 y 24 con enfermedad periodontal crónica grave. Material y método: por examenes de imagen se observo hiperdensidad y en la garragrafia presentaba mayor captación de radiofarmaco en el seno maxilar, para aclarar el diagnóstico, cuya hipótesis también contemplaba además de DP un tumor marron de hiperparatiroidismo y osteosarcoma fueron solicitados examenes de laboratorios, que no presentaba ninguna alteración se marco una biopsia racional para analisis histopatólogico y conclusión del diagnóstico. Resultado: realizada la interrelación de las caracteristicas clínicas, laboratorios, imágenes radiológicas, exámenes histopatológicos, se obtuvo el diagnóstico de DP. Conclusión: despúes del diagnóstico la paciente fue examinada para un tratamiento reumatológico y el tratamiento transcurre ordinariamente con el uso de bifofonato para la reducción de la remodelación ósea siendo este el más ampliamente usado a el ácido zóledronico, además de analgésicos para el control del dolor.

Descriptores: Osteítis Deformante; Diagnóstico por Imagen; Difosfonatos.

INTRODUÇÃO

A doença de Paget ou osteíte deformante foi descrita por James Paget em 1877, sendo definida como uma doença osteometabólica benigna, onde sua fisiopatologia é caracterizada pela reabsorção e deposição anormal e anárquica de osso, sendo este osso menos resistente e mais suscetível à fraturas. Quando há envolvimento maxilar, uma das características clínicas é a leontíase óssea, podendo ocorrer também: obstrução nasal, cornetos aumentados, seios obliterados e desvio de septo secundariamente ${ }^{1-3}$.

A DP tem sua maior incidência em pessoas com idade superior a 40 anos, do sexo 
masculino, brancas e de países de descendência europeia e anglo-saxônica, sendo rara nas Américas4. Ainda não se sabe ao certo sobre sua etiologia, mas segundo alguns autores, pode estar relacionada a fatores genéticos e virais. A genética está associada à história familiar positiva da doença e ao gene sequestossomo 1 (SQSTM1), também conhecido como $p 62^{2,5}$. Os fatores virais, estão relacionados ao vírus da família Paramixoviridae, vírus sincicial respiratório (RSV), sarampo e o vírus da raiva canina $(\mathrm{CDV})^{6}$.

Para o diagnóstico da DP é de fundamental importância o exame clínico sendo, geralmente, a queixa principal o aumento de volume ósseo que pode ou não estar associado à dor. Com a obtenção de dados coletados nesta abordagem semiológica, são solicitados exames complementares imagenológicos, laboratoriais e histopatológico ${ }^{3,7-9}$.

A distribuição da DP pode acometer somente um osso (monostótica) ou mais de um

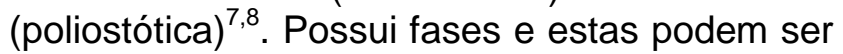
observadas através de exames de imagens, como a radiografia e tomografia computadorizada. As fases são: lítica, mista e blástica, todas as três podendo coexistir no mesmo osso, logo, podem existir densidades aumentadas e diminuídas nos exames de imagens, isso dependerá da fase da doença ${ }^{2,10}$.

Nos exames de imagens, a fase lítica é caracterizada por intensa reabsorção óssea. São observadas áreas de radiolucidez, indicando as reabsorções características da doença,com uma notável ausência de esclerose periférica em torno da osteólise por conta da falta de atividade osteoblástica significativa. Como a doença é assintomática são raros os encontrados clínicos nesta fase $e^{2,11,12}$.

$\mathrm{Em}$ investigação de imagens, na fase mista ocorre tanto reabsorção óssea, quanto deposição anárquica de osso. São observadas trabéculas grosseiras e espessamento da cortical, que ocorre pela reabsorção óssea, seguida de reparo. A grande maioria dos casos de DP são encontrados durante a fase mista $^{2,11,12}$.

$\mathrm{Na}$ fase blástica são notadas áreas de esclerose e aumento do volume ósseo, algumas áreas de esclerose se confluem e áreas escleróticas alternadas tendem a se assemelhar a "flocos de algodão" $2,11,12$.

Outro exame de imagem importante é a cintilografia. É aplicado um radiofármaco por via endovenosa, este localiza áreas que possuem maior fluxo sanguíneo e de formação óssea. Apesar de ser pouco específica, tem maior precisão no tangente às áreas afetadas. $\mathrm{Na}$ cintilografia são identificadas áreas em fase inicial que poderiam não ser notadas na radiografia. Logo, a cintilografia óssea serve para rastreamento do esqueleto, objetivando verificar lesões poliostóticas ${ }^{13,14}$.

Os exames laboratoriais podem fornecer informações importantes para o diagnóstico da DP. Os níveis séricos de cálcio e fosfato são normais na presença de níveis marcadamente elevados de fosfatase alcalina. A fosfatase alcalina no soro é o principal marcador de atividade da doença e deve ser realizada inicialmente $e^{3,7}$.

A biópsia para DP está indicada quando houver dúvida diagnóstica. A histopatologia apresenta numerosos osteoclastos que circundam as trabéculas ósseas e mostram evidência de atividade absortiva e, simultaneamente, há osteoclastos que circundam as trabéculas ósseas, sendo também observada atividade osteoblástica com formação de camada de osteoide em volta das trabéculas ósseas. É visto também tecido conjuntivo fibroso altamente vascularizado substituindo a medula. Um aspecto microscópico característico é a presença de linhas reversas basofílicas no osso, estas linhas indicam a alternância entre fases formativas e reabsortivas de osso, resultando em aparência de "mosaico". Nas fases menos ativas, estão presentes grandes massas de osso denso mostrando linhas reversas proeminentes. Nas três fases existem essas características histopatológicas, no entanto, na lítica há maior atividade osteoclástica, na mista, tanto atividade osteoclástica quanto osteoblástica e na blástica, há maior atuação dos osteoblastos ${ }^{2,3}$.

Desde que os estudos foram iniciados, os tratamentos existentes para a DP visam o controle da dor através de analgésicos e antiinflamatórios não esteroidais, diminuição da reabsorção óssea através de bifosfonatos orais ou intravenosos, para a inibição da proliferação e atividade dos osteoclastos e indução de sua apoptose. Embora o uso de bifosfonatos seja benéfico para os pacientes, é importante que o paciente faça tratamento odontológico prévio, pois há na literatura, associação de diversas complicações, como Osteonecrose Induzida por Bifosfonatos $(\mathrm{OIB})^{15,16}$. O tratamento visa também evitar complicações crônicas geradas pela compressão de estruturas próximas, ou mesmo de fraturas ósseas. Não há tratamento farmacológico para a reabsorção do osso pagético, consequentemente, farmacologicamente não há como reverter as deformidades ósseas $3,7,8,17,18$. Dos bifosfonatos 
usados atualmente, o mais potente parece ser 0 ácido zoledrônico (ZOL), bifosfonato de $3^{\text {a }}$ geração, administrado em uma única dose de $5 \mathrm{mg} / 100 \mathrm{ml}$ por via intravenosa por um período de 15 minutos, sendo eficaz no controle do metabolismo ósseo e tendo como uma de suas vantagens a atuação por anos, o que permite evitar complicações futuras ${ }^{5,18}$.

\section{CASO CLÍNICO}

Paciente do sexo feminino, 63 anos, compareceu à Clínica de Estomatologia da Policlínica Odontológica da UEA, encaminhada após achado radiográfico em imagem pantográfica. $\mathrm{Na}$ anamnese, queixava-se de dor em hemi-maxila esquerda com aumento progressivo local desde a juventude, esta acometia região dos dentes remanescentes ipsilaterais 23 e 24 com doença periodontal crônica grave. Paciente não fazia uso de próteses, pois sentia dor quando algo entrava em contato com a região e com os dentes remanescentes. Quanto à história médica, disse não possuir nenhuma doença preexistente, alegou ainda nascer sem a glândula paratireoide direita. Em história médica familiar relatou que seu pai havia falecido por câncer prostático e sua irmã havia se curado há alguns anos de câncer de mama. Os dentes remanescentes apresentavam doença periodontal crônica grave, motivo que levara a perder quase todos os elementos dentários. Em radiografia panorâmica (Figura 1), no seio maxilar esquerdo foram observadas áreas radiopacas entremeadas por áreas radiolúcidas, que se assemelhavam a "flocos de algodão", característico da fase blástica da DP.

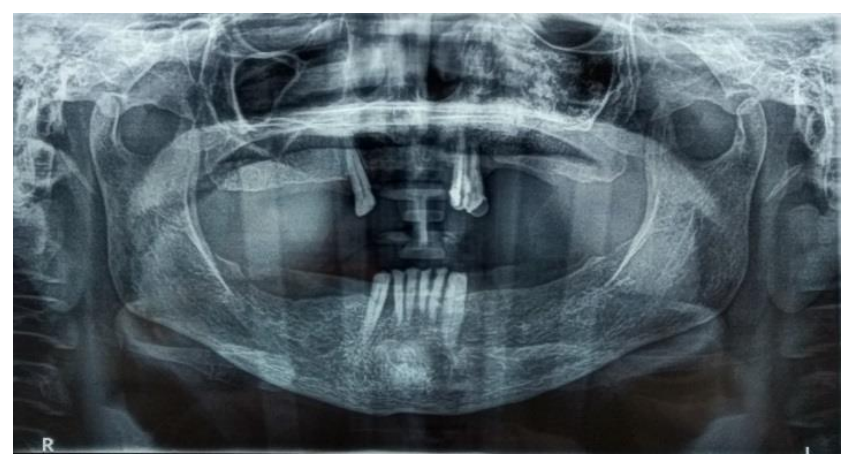

Figura 1: Padrão tipo "flocos de algodão" difuso (alternância de áreas de esclerose e radiolucência) por quase toda a região de seio maxilar esquerdo. Os dentes remanescentes apresentavam doença periodontal crônica. Foto: Pinheiro T.N.

Foi solicitada

Tomografia

Computadorizada para visualização da abrangência da área acometida pela lesão na região de cabeça e pescoço (Figura 2), bem como as características da mesma. $\mathrm{Na}$ tomografia computadorizada foram observadas áreas hiperdensas irregulares e multiloculares que preenchiam quase toda região de seio maxilar esquerdo e áreas de hipodensidade, também multiloculares, que estavam entre as áreas de hiperdensidade, mas em menor abrangência e cortical óssea bem delimitada (Figura 2 e 3). A tomografia computadorizada em 3D - compara as vistas lateral esquerda e direita, sendo possível notar maior volume ósseo na maxila esquerda em decorrência da deposição anárquica óssea (Figuras 4 e 5).

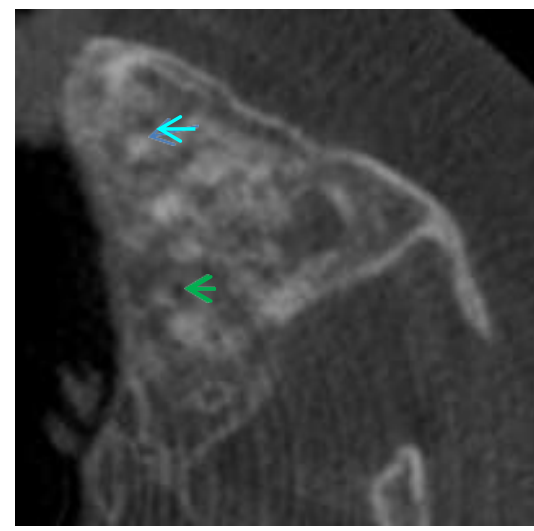

Figura 2: Corte axial evidenciando seio maxilar esquerdo da tomografia computadorizada, lesão apresentava áreas hiperdensas irregulares e multiloculares (azul) que preenchiam quase toda região de seio maxilar esquerdo $e$ áreas de hipodensidade, também multiloculares (verde). Foto: Pinheiro T.N.

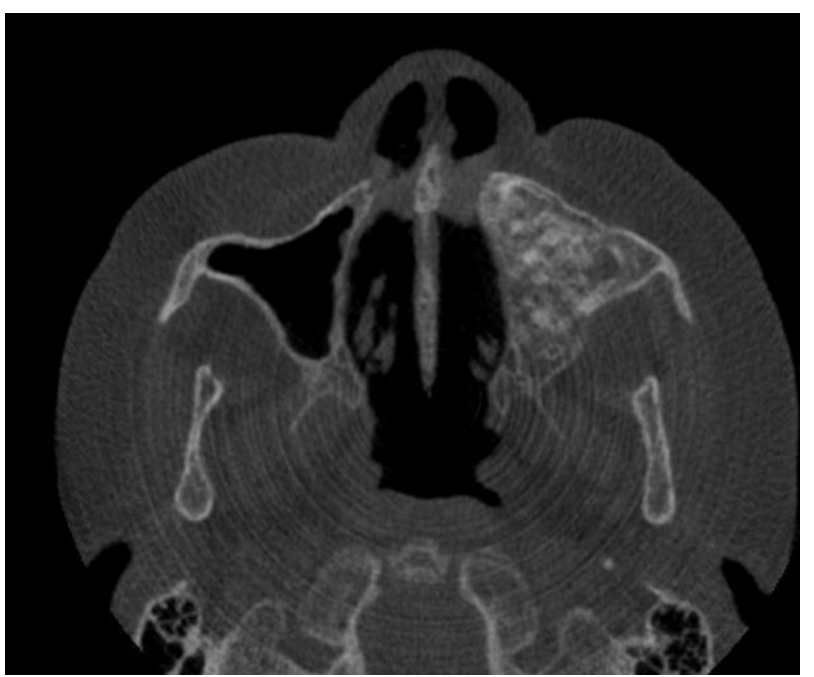

Figura 3: Corte axial da tomografia computadorizada mostrando abrangência da área acometida pela lesão e o aspecto da lesão em região de seio maxilar esquerdo. Foto: Pinheiro T.N.

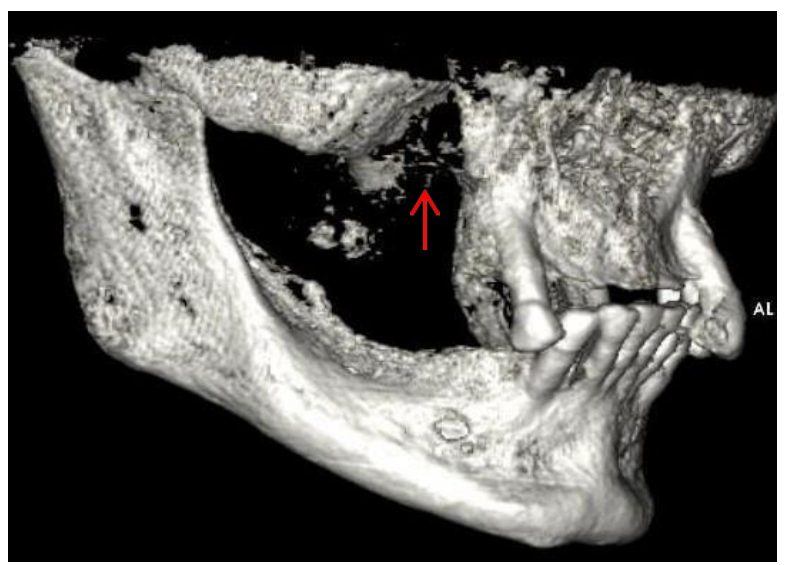

Figura 4: Tomografia computadorizada 3D vista lateral direita demonstrando falha óssea na hemi-maxila direita (vermelho), devido a perdas dentárias. Foto: Pinheiro T.N. 


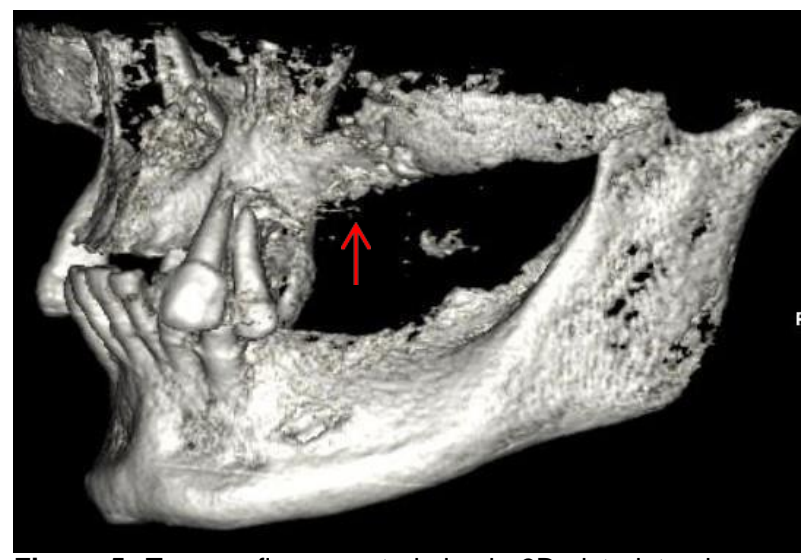

Figura 5: Tomografia computadorizada 3D vista lateral esquerda apresenta tecido ósse de forma desorganizada em região de maxila (vermelho), devido à deposição óssea anárquica. Foto: Pinheiro T.N.

Foi ainda solicitado o exame de cintilografia para encontrar outros sítios da lesão, em sua vista anterior, observou-se maior captação de radiofármaco em seio maxilar esquerdo, cóccix e tubérculo ilíaco direito e esquerdo (Figura 6A), já por vista posterior foi observada captação de radiofármaco na área da articulação sacroilíaca do lado direito, esquerdo e cóccix (Figura 6B). A captação do radiofármaco apresentava-se muito mais intensa na região de seio maxilar esquerdo do que nas outras regiões (Figura 6A).
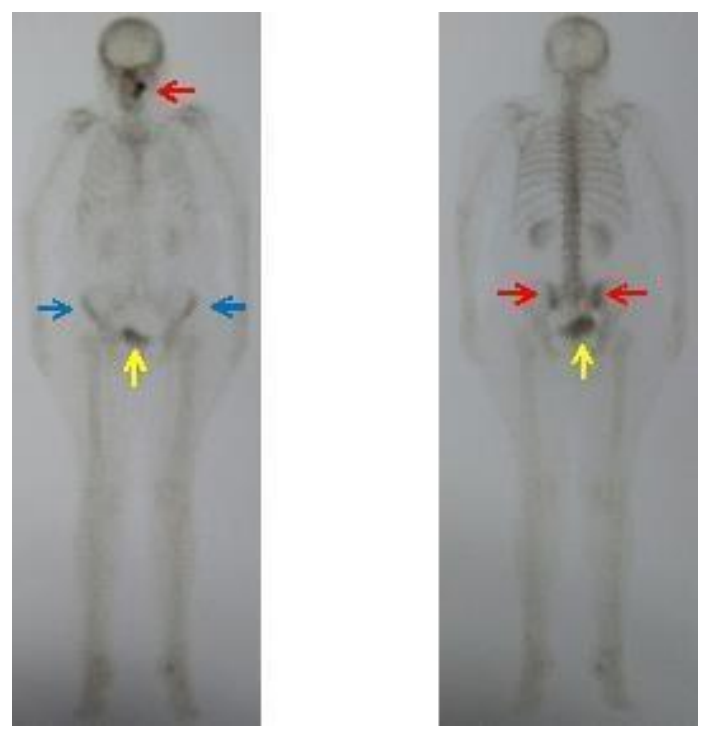

Figura 6: A) Vista anterior - Maior captação de radiofármaco na área de seio maxilar esquerdo (vermelho), cóccix (amarelo) e tubérculo ilíaco direito e esquerdo (azul). B) Vista anterior - Maior captação de radiofármaco em área da articulação sacroilíaca do lado direito e esquerdo (vermelho) e cóccix (amarelo). Foto: Pinheiro T.N. Foto: Pinheiro T.N.

Foi feita a inter-relação das características clínicas e imagenológicas, para definir o diagnóstico, cujas hipóteses contemplavam, além de DP, tumor marrom do hiperparatiroidismo e osteossarcoma, foram solicitados alguns exames laboratoriais: Investigando Tumor marrom do hiperparatiroidismo: TSH - Hormônio Tireoestimulante Ultra Sensível, creatinina, PTH paratormônio, T3 e T4; DP: fosfatase alcalina, albumina, microalbumina $e$ TGP; e Osteossarcoma: cálcio sérico, fosfatase alcalina, aldolase e calcitonina (Figura 7).

\begin{tabular}{|c|c|c|c|}
\hline EXAME & $\begin{array}{l}\text { VALOR DO } \\
\text { EXAME }\end{array}$ & $\begin{array}{l}\text { VALOR DE } \\
\text { REFÊNCIA }\end{array}$ & RESULTADO \\
\hline TSH & 2,547 Uuil $/ \mathrm{mL}$ & $\begin{array}{c}0,400 \text { a } 5,800 \\
\text { Uui/mL }\end{array}$ & \multirow{12}{*}{$\begin{array}{c}\text { Valores dentro da } \\
\text { normalidade }\end{array}$} \\
\hline PTH & $43,1 \mathrm{pg} / \mathrm{mL}$ & 16 e $87 \mathrm{pg} / \mathrm{mL}$ & \\
\hline CREATININA & $0,82 \mathrm{mg} / \mathrm{dL}$ & $0,53 \mathrm{~A} 1,00 \mathrm{MG} / \mathrm{dl}$ & \\
\hline T3 & $88,2 \mathrm{ng} / \mathrm{dL}$ & 60,0 a $215,0 \mathrm{ng} / \mathrm{dL}$ & \\
\hline T4 & $6,2 \mathrm{ug} / \mathrm{dL}$ & 4,8 a 13,7 ug/dL & \\
\hline Fosfatase alcalina & $216 u / L$ & 80,0 a $300,0 \mathrm{U} / \mathrm{L}$ & \\
\hline MICROALBUMINA & $3,3 \mathrm{mg} / \mathrm{g}$ & $<26,0 \mathrm{mg} / \mathrm{g}$ & \\
\hline ALBUMINA & $3,6 \mathrm{~g} / \mathrm{dL}$ & 3,5 a $5,5, \mathrm{~g} / \mathrm{dL}$ & \\
\hline TGP & $34,1 \mathrm{U} / \mathrm{L}$ & Até $41 \mathrm{U} / \mathrm{L}$ & \\
\hline CALCITONINA & $<2,0 \mathrm{pg} / \mathrm{mL}$ & $<5,0 \mathrm{pg} / \mathrm{ml}$ & \\
\hline CALCIO SÉRICO & $9,2 \mathrm{mg} / \mathrm{dL}$ & 8,4 a $10,2 \mathrm{mg} / \mathrm{dL}$ & \\
\hline ALDOLASE & $6,0 \cup / L$ & Até $7,6 \cup / L$ & \\
\hline
\end{tabular}

Figura 7: Exames laboratoriais solicitados e resultados

Todos os exames laboratoriais se encontravam dentro da normalidade, consequentemente, não dando conclusividade ao diagnóstico, desta forma, optou-se pela realização de biopsia incisional e, para isso, foram solicitados os seguintes exames laboratoriais: hemograma completo, coagulograma e glicemia em jejum, com os resultados dentro do padrão de normalidade. No dia da biópsia foi aferida a pressão sistólica e diastólica, que resultara em $129 \mathrm{mmHg}$ x 85 $\mathrm{mmHg}$, estando também dentro dos padrões de normalidade, com frequência cardíaca de 53 bpm.

Após a antissepsia intra e extraoral, foi feita técnica anestésica utilizando Articaína 4\% com epinefrina1:1000 associado a Lidocaína 2\% com epinefrina 1:100.000, sendo feito 0 bloqueio do nervo alveolar superior médio, nervo alveolar superior posterior e palatino maior. Foi feita incisão semicircular com lâmina $15 \mathrm{c}$ acima da região onde estariam $2^{\circ}$ pré-molar e $1^{\circ}$ molar superior esquerdo (Figuras 8 e 9), procedeu-se o descolamento com o descolador de Molt $n^{\circ} 05$, após descolamento, a região foi irrigada com soro fisiológico $0,9 \%$ para visualização da área. Para coleta de material para exame de biópsia, foi utilizada broca trefina em alta rotação, esta posicionada perpendicularmente ao osso, foi introduzida em $1 \mathrm{~cm}$ (Figura 10). Removido o tecido, este se apresentava como um fragmento de tecido duro, forma e superfície cilindrica, coloração acastanhada, medindo 1,0x 0,3 x 0,1 cm (Figura 11 e 12), estas áreas amarronzadas levaram, em um primeiro 
momento, à suspeita de tumor marrom do hiperparatiroidismo. Foi realizada sutura com 4 pontos simples utilizando fio de nylon 04 (Figura 13). Após a cirurgia, foram prescritos antiinflamatório por dois dias, analgésico e demais recomendações pós-operatórias. Após duas semanas a área incisada estava em perfeita cicatrização tecidual (Figura 14).

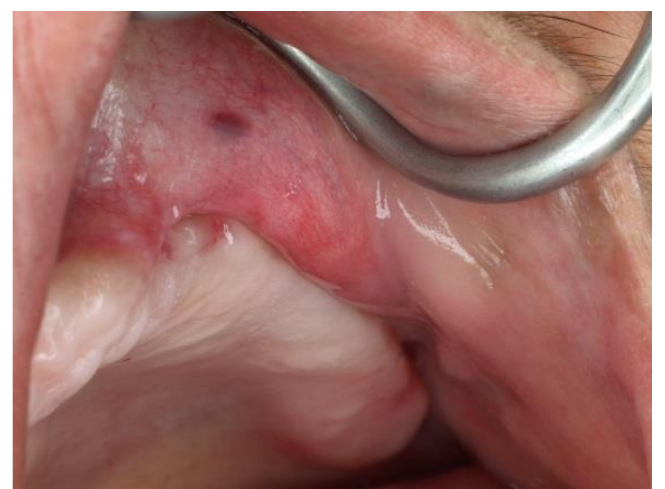

Figura 8: Área de incisão, mucosa íntegra. Foto: Pinheiro T.N.

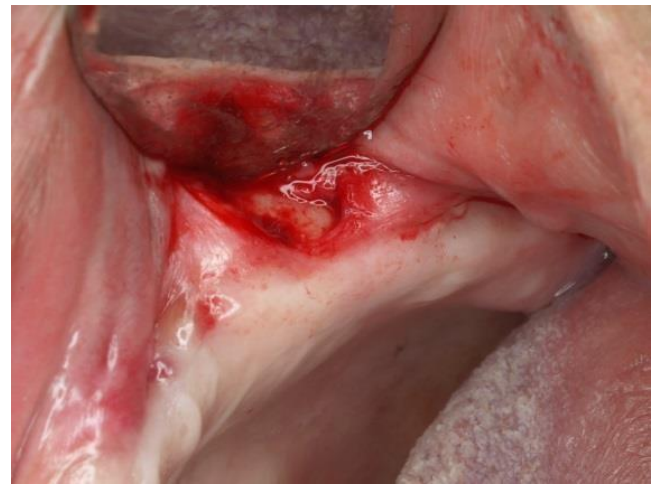

Figura 9: Incisão do tipo semicircular na região acima do rebordo de pré-molares e primeiro molar. Foto: Pinheiro T.N.

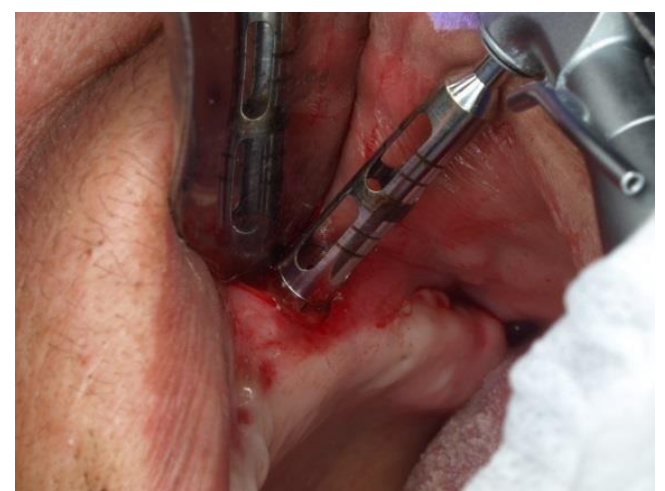

Figura 10: Remoção de material para biópsia utilizando broca trefina de $5 \mathrm{~mm}$. Foto: Pinheiro T.N.

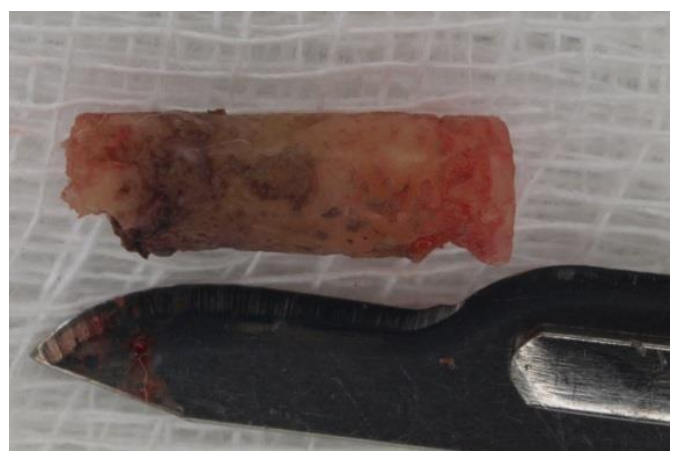

Figura 11: Tecido ósseo biopsiado com áreas amarronzadas. Dimensões: $1,0 \times 0,3 \times 0,1 \mathrm{~cm}$. Foto: Pinheiro T.N.

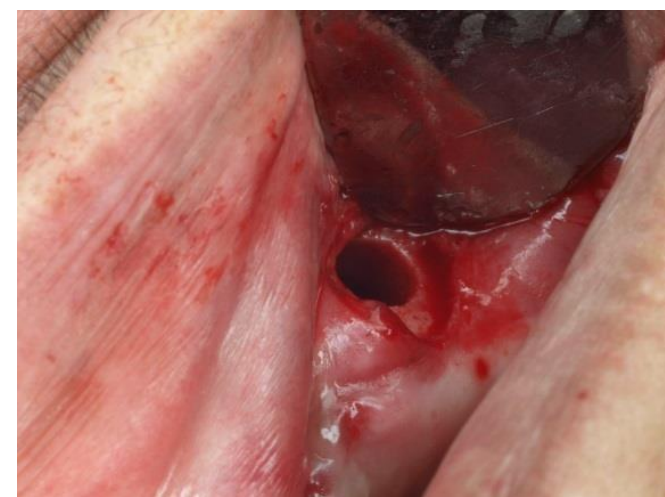

Figura 12: Área cirúrgica após remoção da amostra. Foto: Pinheiro T.N.

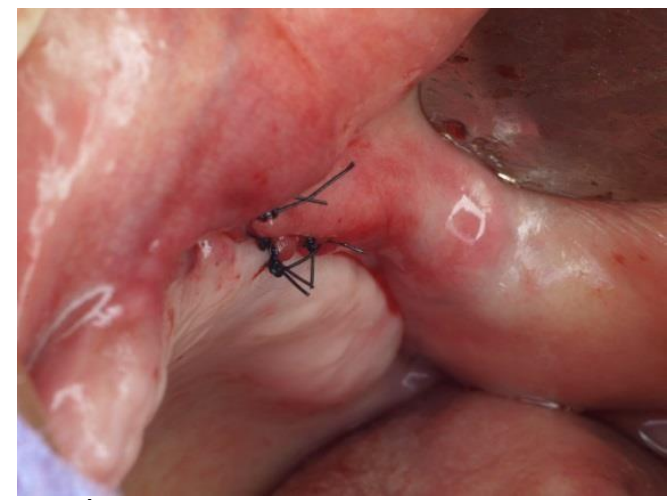

Figura 13: Área cirúrgica após sutura. 4 pontos simples com fio de nylon 04 Foto: Pinheiro T.N.

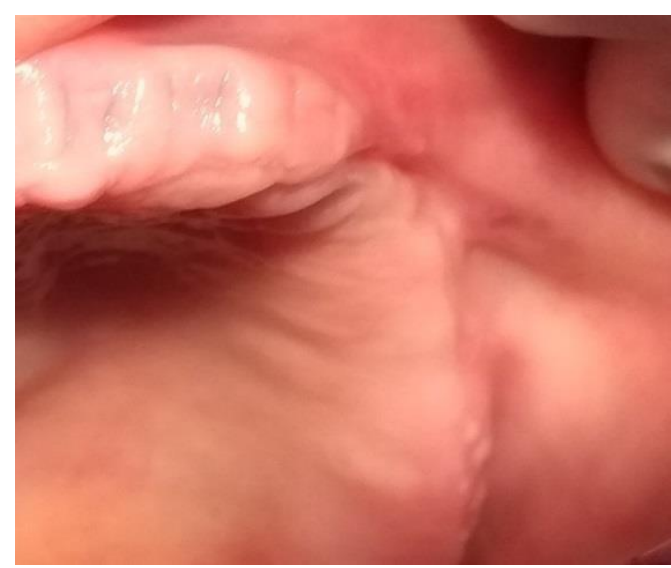

Figura 14: Área de incisão após duas semanas, mucosa íntegra. Foto: Pinheiro T.N.

O material coletado da biópsia incisional foi encaminhado ao Laboratório de Patologia da Escola Superior de Ciências da Saúde da Universidade do Estado do Amazonas (UEA), onde foi submetido à análise histopatológica. Os cortes microscópicos revelavam fragmento de tecido ósseo com trabéculas irregulares, áreas displásicas formando mosaicos e outras inclusões celulares entremeadas por áreas acelulares ricas em linhas de reversão por vezes de aspecto cementóide. Os espaços medulares apresentavam-se ora preenchidos por tecido adiposo, ora por tecido conjuntivo frouxo pouco celularizado (Figuras 15 a 19). O diagnóstico foi Doença de Paget e dependeu da inter-relação de características clínicas, laboratoriais, imagenológicas que foram 


\section{disponibilizadas pelo solicitante $e$ as características microscópicas obtidas}

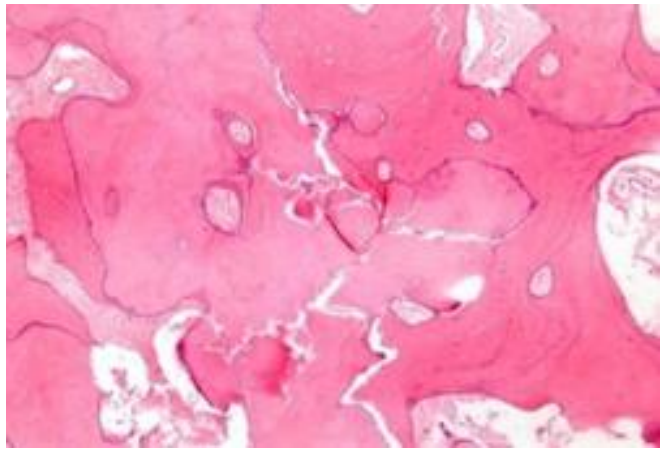

Figura 15: Tecido ósseo trabecular com: trabéculas irregulares áreas displásicas formando mosaicos, áreas abundantes em inclusões celulares, entremeadas por áreas acelulares ricas em linhas de reversão por vezes de aspecto cementóide. Os espaços medulares apresentam-se ora preenchidos por tecido adiposo, ora por tecido conjuntivo frouxo pouco celularizado. Foto: Pinheiro T.N.

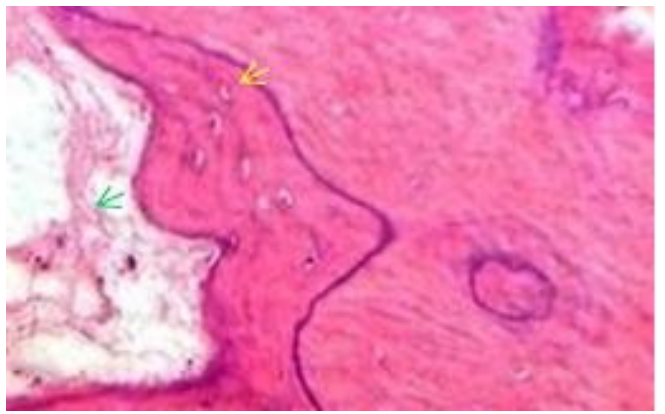

Figura 16: Trabéculas ósseas irregulares com inclusões celulares (amarelo) e espaço medular preenchido com tecido conjuntivo frouxo pouco celularizado (verde). Foto: Pinheiro T.N

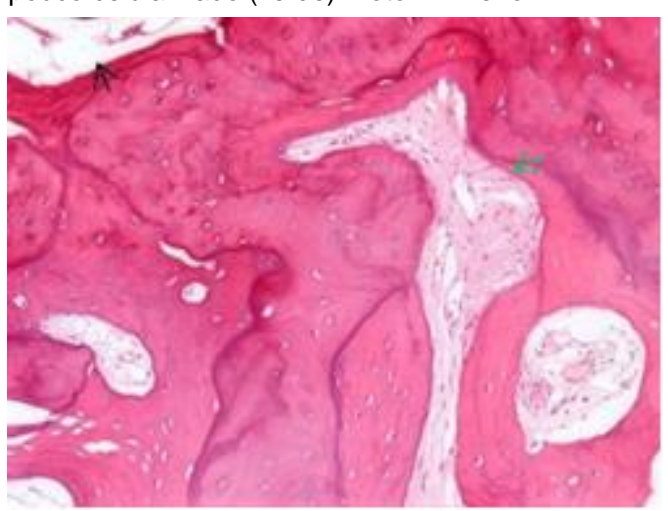

Figura 17: Espaços medulares preenchido com tecido conjuntivo frouxo pouco celularizado (verde) e tecido adiposo (preto). Foto: Pinheiro T.N.

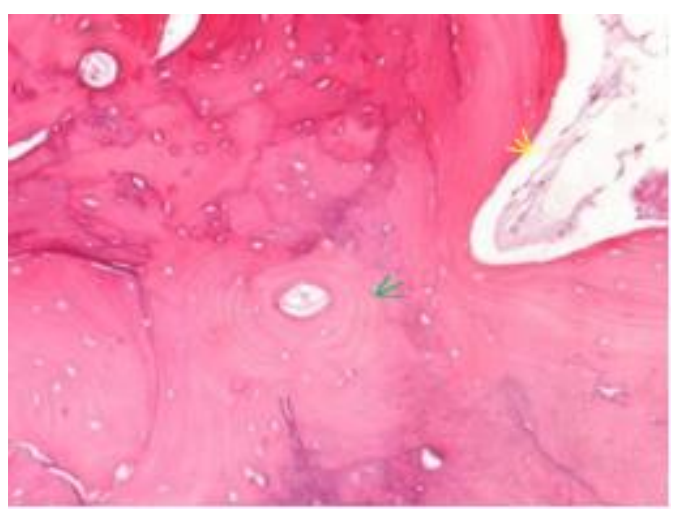

Figura 18: Espaço medular preenchido com tecido conjuntivo frouxo pouco celularizado (amarelo) e linhas de reversão (verde). Foto: Pinheiro T.N.

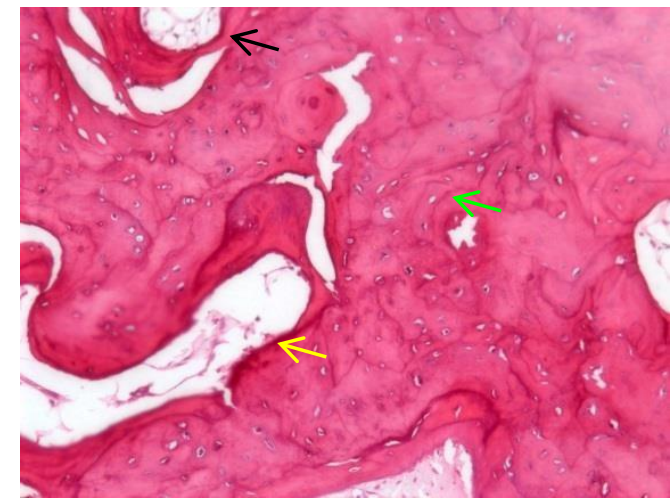

Figura 19: Espaços medulares preenchido com tecido conjuntivo frouxo pouco celularizado (amarelo) e tecido adiposo (preto), linhas de reversão com aspecto cementóide (verde). Foto: Pinheiro T.N.

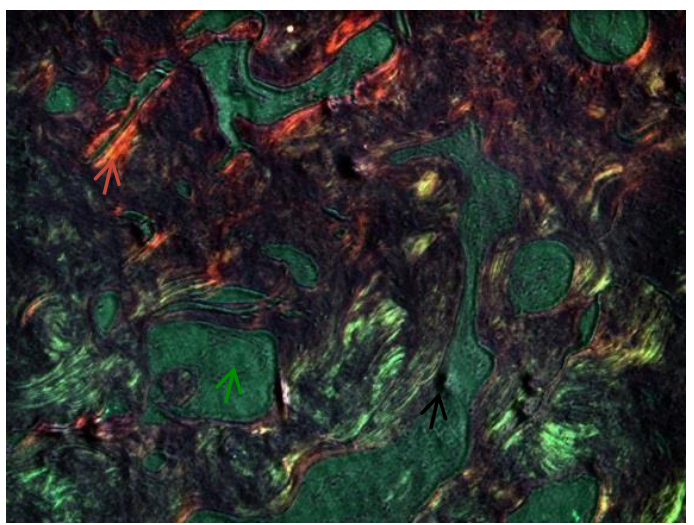

Figura 20: Microscopia com luz polarizada - Tecido ósseo (preto) entremeado por tecido conjuntivo frouxo (verde esmeralda e vermelho/laranja). Foto: Pinheiro T.N.

Após o diagnóstico, a paciente foi encaminhada para tratamento reumatológico, para a condição de base e odontológico, na Policlínica Odontológica da UEA (POUEA), para tratamento reabilitador funcional e estético. Atualmente, o tratamento da DP é feito com uso de analgésico para redução da dor e de bifosfonatos, onde o mais usado é o ácido zoledrônico este atuando, principalmente, no controle da remodelação óssea, no entanto, alguns estudos o associam à osteonecrose induzida por bifosfonato, desta forma é importante que o tratamento odontológico seja feito previamente ao tratamento da DP, para que não haja complicação durante o tratamento com o ácido zoledrônico.

CONCLUSÃO

Este caso demonstra a importância do exercício propedêutico para o Cirurgião Dentista, na assertividade diagnóstica de Doença de Paget, importante doença sistêmica, a partir de uma manifestação atípica em seio maxilar de paciente senil do sexo feminino destacando, com isso, a importância e relevância do olhar estomatológico no universo da interdisciplinaridade. 


\section{REFERÊNCIAS}

1. Paget J. On a Form of Chronic Inflammation of Bones (Osteitis Deformans). Med Chir Trans. 1877;60:37-64.9.

2. Neville BW, Damm DD, Allen CM, Bouquot JE. Patologia Oral \& Maxilofacial. 2.ed. Rio de Janeiro: Guanabara Koogan;2004.

3. Regezi JA, Sciubba JJ, Jordan RCK. Patologia Bucal: Correlações Clinicopatológicas. 5. ed. Rio de Janeiro: Elsevier, 2008

4. Cooper C, Harvey NC, Dennison EM, van Staa TP. Update on the epidemiology of Paget's disease of bone. J Bone Miner Res. 2006;21 (Suppl 2):P3-8.

5. Griz L, Caldas G, Bandeira C, Assunção V, Bandeira F. Paget's disease of bone. Arq Bras Endocrinol Metabol. 2006;50(4):814-22.

6. Friedrichs WE, Reddy SV, Bruder JM, Cundy T, Cornish J, Singer FR, Roodman GD. Sequence analysis of measles virus nucleocapsid transcripts in patients with Paget's disease. J Bone Miner Res. 2002;17(1):145-51.

7. Brasil. Ministério da Saúde Secretaria de Atenção à Saúde. Doença de Paget - osteíte deformante. Protocolo Clínico e Diretrizes Terapêuticas. Portaria SAS/MS no 456 de 21 de maio de 2012. Brasília: 2012. p. 169-184.

8. Langston AL, Ralston SH. Management of Paget's disease of bone. Rheumatology. 2004;43(8):955-59.

9. Pereira CU, Rosa HRS, Pereira JC, Anjos ED.; Carvalho RWF. Doença de Paget do complexo crânio - maxilo - facial: revisão crítica da literatura. Rev cir traumatol buco-maxilo-fac. 2008;8(2):15-24.

10.Grandi G, Santos MESM, Borges $\mathrm{HO}$ e Sant'ana Filho M. Doença de Paget: relato de casos em relação ao diagnóstico diferencial. Rev cir traumatol buco-maxilo-fac. 2005; 5(3):27-34,

11.José FF, Pernambuco ACA, Amaral DT. Doença de Paget do osso. Einstein; 2008; 6(1):S79-88.

12. Smith SE, Murphey MD, Motamedi K, Mulligan ME, Resnik CS, Gannon FH. From the archives of the AFIP. Radiologic spectrum of Paget disease of bone and its complications with pathologic correlation. Radiographics. 2002;22(5):1191-216.

13. Spina LDC, Carvalho FCR, Eksterman LF, Torres SG, Janini MER e Farias MLF. Doença de Paget do Complexo Crânio-Maxilo-Facial: revisão crítica da literatura. Arq Bras Endocrinol Metabol. 2000;44(3):266-72.

14. Brasil. Ministério da Saúde. Secretaria de Atenção à Saúde. Instituto Nacional de Câncer. Coordenação de Assistência. Abordagem inicial dos tumores ósseos.INCA: Rio de Janeiro. 2004. p. 1-24.
15.Spezzia S. Implicações odontológicas do emprego dos bisfosfonatos: osteonecrose no complexo ósseo maxilo-mandibular. RCO. 2019;3(2):27-34.

16. Moraes SL, Afonso AMP, Santos RG, Mattos RP, Oliveira MTF, Barbosa DZ, et al. Riscos e complicações para os ossos da face decorrentes do uso de bisfosfonatos. Rev Bras Odontol. 2013;70(2):114-19

17. Castro GRW, Castro SAF, Pereira IA, Zimmermann AF, Toscano MA, Neves FS et al. Determinantes da qualidade de vida na doença de Paget óssea. Rev Bras Reumatol, 2017;57(6):566-73.

18. Griz L, Colares V, Bandeira F. Tratamento da doença de Paget óssea: importância do ácido zoledrônico. Arq Bras Endocrinol Metab. 2006;50(5):845-51. 


\section{CONFLITO DE INTERESSES}

Os autores declaram não haver conflitos de interesse

\section{AUTOR PARA CORRESPONDENCIA}

\section{Vivian Bentes de Oliveira}

Rua Dr Cirilo, n17, Bairro Zumbi I,

69084140 Manaus - Amazonas, Brasil

Email: vivianbentesdeoliveira1@gmai.com

Submetido em 30/04/2020

Aceito em 23/10/2020 